\title{
FRAGILIDADE AMBIENTAL POTENCIAL DA BACIA HIDROGRÁFICA DO RIO CASTÁN, ESTADO TRUJILLO - VENEZUELA
}

\author{
Lisbeth Segovia Materano \\ Universidad de Los Andes, Departamento de Ciencias Sociales- Área de Geografia \\ Trujillo, estado Trujillo, Venezuela \\ segoviam.lisbeth@gmail.com \\ Jorge Luis Silva Brito \\ Universidade Federal de Uberlândia, Instituto de Geografia, Pós-Graduação em Geografia \\ Uberlândia, MG, Brasil \\ jbrito@ufu.br
}

\begin{abstract}
RESUMO
As drenagens da bacia hidrográfica do rio Castán localizada no estado Trujillo -Venezuela são as fontes abastecedoras para todas as atividades desenvolvidas na capital do estado e nas regiões circunvizinhas. O presente trabalho teve por objetivo modelar os distintos níveis de fragilidade ambiental potencial da bacia hidrográfica do rio Castán. Inicialmente foram realizados os mapeamentos temáticos de declividade, distância até drenagens, solos e precipitação média anual. Posteriormente, utilizou-se a metodologia de Análise Multicritério, por meio do Processo de Análise Hierárquica para a determinação da importância dos critérios e obtenção do índice e razão de consistência da matriz e, por último, realizou-se uma sobreposição das camadas no SIG mediante de Combinação Linear Ponderada.Obtiveramse como resultados cinco níveis de fragilidade ambiental potencial: Muito baixa (3\%), Baixa (22\%), Moderada (36\%) Alta (29\%) e Muito Alta (10\%). As classe Alta e Muito Alta somadas representam a maior extensão da área da bacia, devendo-se levar em consideração tais características de fragilidade para elaboração de planos de desenvolvimento e equilíbrio ambiental da bacia.
\end{abstract}

Palavras-chave: Geoprocessamento. Análise Multicritério. Ordenamento do território. Conservação ambiental.

\section{POTENTIAL ENVIRONMENTAL FRAGILITY OF THE CASTÁN RIVER BASIN IN THE TRUJILLO STATE -VENEZUELA.}

\begin{abstract}
The Castán river basin located in the Trujillo state - Venezuela is the only source of water for all the activities carried out in the state capital and in the surrounding regions; the main idea of this paper was model the different levels of potential environmental fragility in the aforementioned geographic space.Initially, thematic mappings of slope, distance to drainage, soil and annual mean precipitation were performed; Subsequently, the methodology of Multicriteria Analysis was used, through the Hierarchical Analysis Process to determine the importance of the criteria and obtain the index and consistency ratio of the matrix, and finally, an overlap of the layers in the GIS was performed of Weighted Linear Combination. Five levels of potential environmental fragility were obtained: Very low $(3 \%)$, Low $(22 \%)$, Moderate $(36 \%)$ High $(29 \%)$ and Very High (10\%). The High and Very High summed classes represent the largest extension of the basin area, taking into account such fragility characteristics to elaborate development plans and environmental balance of the basin.
\end{abstract}

Keywords: Geoprocessing.Algebra of maps.Spatial Multicriteria Evaluation. Environmental Conservation.

\section{INTRODUÇÃO}

A destruição dos espaços naturais pela ação antrópica é um fato que repercute nos recursos solo e água. Muitas vezes, esses danos são causados por atividades agrícolas e produtivas não planejadas e que não levam em consideração a conservação ambiental. Uma das principais ferramentas utilizadas

Caminhos de Geografia $\quad$ Uberlândia - MG $\quad$ v. 21, n. $73 \quad$ Mar/2020 $\quad$ p. 86-97 Página 86


pelos órgãos públicos para evitar danos ambientais e fortalecer os planos de organização territorial são mapeamentos da fragilidade ambiental, os quais permitem avaliar as potencialidades do meio ambiente de forma integrada, compatibilizando suas características naturais com suas restrições, podendo orientar a tomada de decisões, em virtude de apresentar as informações necessárias para identificar as melhores ações a serem implementadas para a sustentabilidade ambiental (KAWAKUBO et al., 2005; SPORL, 2007).

Em termos gerais, a fragilidade ambiental pode ser considerada como a debilidade intrínseca do ambiente para sofrer dano ocasionado pela dinâmica ambiental, sendo relacionada usualmente com a erosão do solo e posterior assoreamento dos rios. Frequentemente se faz referência à fragilidade potencial e fragilidade emergente; a primeira pode ser conceituada como a susceptibilidade natural de um ambiente em função de suas características físicas como a declividade, índice de pluviosidade, tipo de solo, entre outros (SCHIAVO et al.,2016), enquanto a fragilidade emergente inclui ademais das características mencionadas, os graus de proteção dos diferentes tipos de uso e cobertura vegetal e do território sobre o ambiente, ou seja, considera também a cobertura da terra e intervenções humanas (VALLE et al., 2016). Vale lembrar o conceito de áreas frágeis, que de acordo com França (2018), são aquelas que por suas características, apresentam sensibilidade aos impactos ambientais adversos, baixa resistência e pouca capacidade de recuperação.

O avanço e acessibilidade dos Sistemas de Informação Geográfica (SIG's), dados e informações obtidos por satélites, junto com as técnicas de geoprocessamento permitem a avaliação de situações ambientais com maior precisão, alem de diminuir os custos e flexibilizar o esforço humano na coleta e reorganização dos dados. Outro fator que merece ser mencionado é a aplicação de metodologias como a Análise Multicritério (AMC), por meio de SIG's que auxiliam os estudos ambientais e permitem uma maior representatividade das variáveis territoriais.

Dentre as técnicas de AMC mais utilizadas para ponderar os critérios, destaca-se o denominado Processo de Análise Hierárquica (Analytic Hierarchy Process - AHP), proposto por Saaty (1981), o qual busca um aumento da fidedignidade ao garantir maior consistência das ponderações realizadas. Nas palavras de Eastman (2006), esta metodologia confere um avanço em relação aos procedimentos convencionais com layers no SIG's, para a priorização de áreas.

É de conhecimento geral que as bacias hidrográficas constituem o espaço de análise ambiental fundamental, nesses territórios confluem diversas características topográficas, hidrológicas, ecológicas, sociais e econômicas. Numa perspectiva mais ampla, Ferreira (2016) comenta que para ter um manejo sustentável é indispensável apresentar como ponto inicial estudos interdisciplinares em bacias hidrográficas, fomentando assim o planejamento territorial e uso racional dos recursos presentes em elas, ressaltando o manejo integrado da água que é um recurso indispensável para a vida.

Estudos com a finalidade de ordenação do território da bacia do rio Castán, localizada no estado Trujillo - Venezuela são de fundamental importância, uma vez que o rio que drena essa bacia é a única fonte abastecedora de água para todas as atividades desenvolvidas na capital do estado e nas regiões circunvizinhas.Valera e Castellano (2010) afirmam que esta bacia encontra-se submetida a fortes pressões oriundas da demanda de água para irrigação e pela ocupação de espaços com limitações ambientais. Nesse local, é crescente a expansão da fronteira agrícola, e o desenvolvimento desorganizado de vias e estabelecimentos urbanos, desconsiderando os critérios básicos de planificação e ordenação do território.

A bacia do rio Castán possui em seu território atividades socioeconômicas de risco potencial de degradação, associadas tanto à supressão da vegetação quanto à degradação de recursos hídricos e dos solos. Diante disso, a modelagem da fragilidade ambiental potencial surge como uma importante ferramenta que pode contribuir com o gerenciamento da bacia, na medida em que este resultará em um material de utilidade para seu planejamento e crescimento ordenado e sustentável.

Nesse contexto, o objetivo do trabalho é espacializar os distintos níveis de fragilidade ambiental potencial na bacia hidrográfica do rio Castán no estado Trujillo na Venezuela utilizando Análise Multicritério (AMC), e mais especificamente a técnica de AHP, em ambiente de SIG's. 


\section{Localização da área de estudo}

A bacia do rio Castán localiza-se ao ocidente da Venezuela, especificamente no estado Trujillo, entre as coordenadas geográficas de $9^{\circ} 13^{\prime} 51^{\prime \prime}$ e $9^{\circ} 27^{\prime} 13^{\prime \prime}$ de latitude ao Norte do Equador e $70^{\circ} 17^{\prime} 24^{\prime \prime}$ e $70^{\circ} 32^{\prime} 37^{\prime \prime}$ de longitude oeste do meridiano de Greenwich. Ocupa uma superfície de $397 \mathrm{~km}^{2}$, sendo que $88,5 \%$ da bacia pertence ao município Trujillo e o restante pertence ao município Pampanito. Vale ressaltar que o município Trujillo é o que aloja a capital política - administrativa do estado homônimo, e as drenagens da bacia do rio Castán são as fontes fornecedoras de água para todas as atividades ali desenvolvidas. A bacia hidrográfica do rio Castán, drena suas águas para o rio Jimenez, que deságua no rio Motatán, que é parte da bacia hidrográfica do Lago de Maracaíbo. A figura 1 exibe a localização da área objeto de estudo nesta pesquisa.

Figura 1 - Localização da bacia hidrográfica do rio Castán.

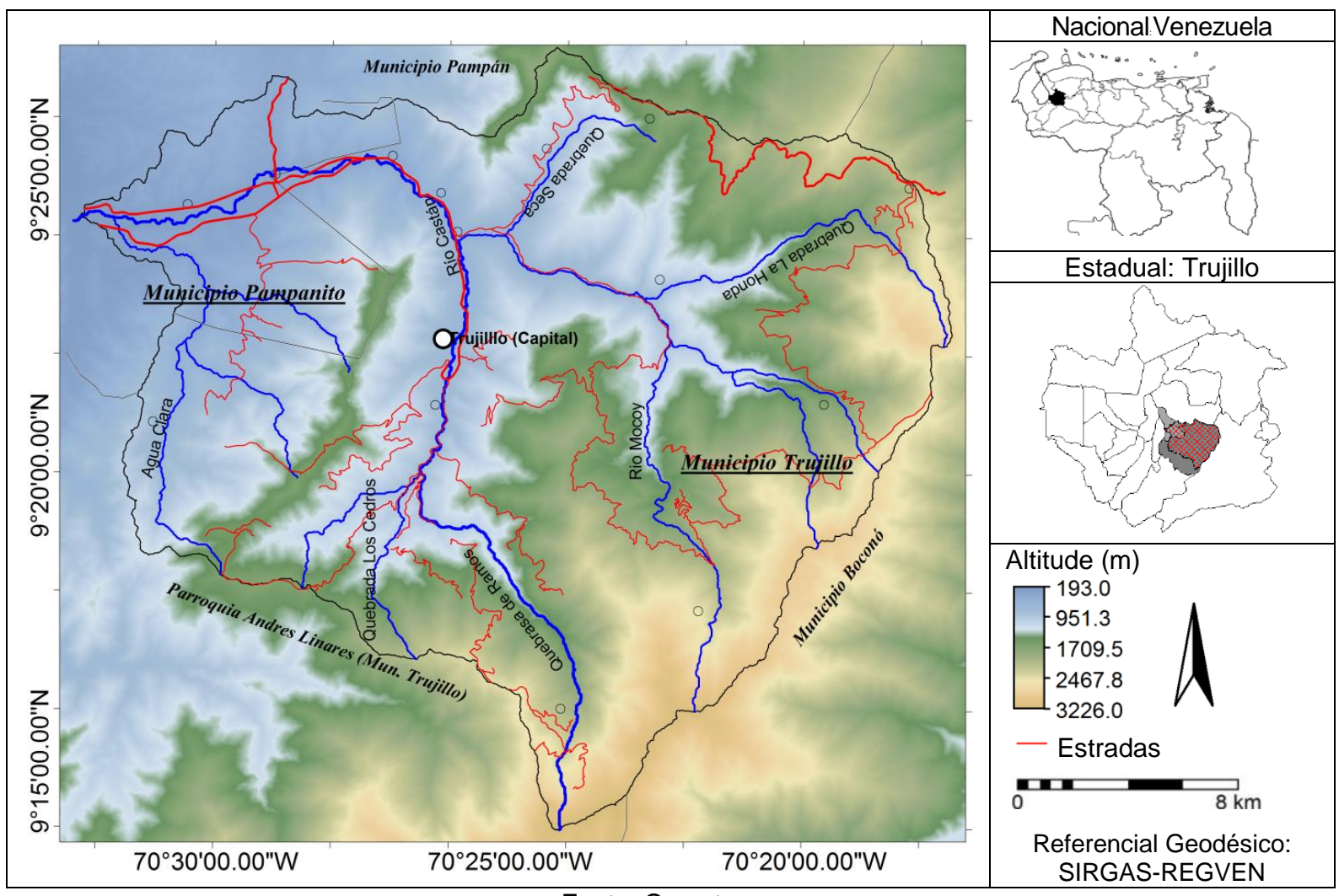

Fonte: Os autores.

\section{METODOLOGIA}

De maneira global, o método da pesquisa é dedutivo, que se caracteriza por ir do geral ao particular. Para Pagot (2007), o método dedutivo nos estudos geográficos se fundamenta no aproveitamento de modelos físicos ou matemáticos que permitam estimar os parâmetros a partir dos dados obtidos mediante geotecnologias e seu posterior processamento. Incialmente foi realizada a etapa de inventário e posteriormente a ponderação e integração das camadas no SIG.

\section{Primeira etapa: Inventário.}

$\mathrm{Na}$ etapa do inventário foram elaborados os mapas temáticos de: declividade, distância até drenagens, solos, e distribuição média das precipitações. Primeiramente, foram empregados atributos topográficos derivados de um modelo digital de elevação (MDE) obtido por meio de imagens do sensor Palsar a bordo do satélite Alos. Essas imagens têm 16 bits de resolução radiométrica e resolução espacial de 12,5 x 12,5 m. Ressalta-se que o sensor é capaz de obter imagens diurnas e noturnas sem a interferência de nebulosidade. Neste caso a camada representativa das elevações foi obtida gratuitamente do site Alaska Satellite Facility. 
A rede de drenagem foi determinada levando em consideração as variáveis topográficas relacionadas com as curvas de nível e o mapa de drenagens do estado Trujillo. Para a construção de um MDE consistente, o modelo em questão foi otimizado, utilizando o mapa das drenagens, e depois se recorreu à aplicação do Polinômio proposto por Horn (1981) para gerar o mapa de declividade. O mapa de solos foi adquirido de fontes secundárias (Mapa Zonificación Agroecológica para el estado Trujillo), georreferenciado e digitalizado.

Para a construção do mapa de precipitação foram obtidos os dados de precipitação do site do Instituto Nacional de Meteorología e Hidrografía (INAMEH), instituição que pertence ao Ministerio del Poder Popular para Ecosocialismo y Aguas (MINEA), e que é o órgão gerenciador dos dados referentes com as atividades hidrometeorológicas na Venezuela.

Uma vez obtidas e processadas as tabelas da informação anual de precipitação para o período de 1997 ate 2017 para o estado Trujillo, foram seleccionadas as três estações meteorológicas dentro da bacia hidrográfica do rio Castán (Páramo La Cristalina, Páramo de Ortiz, Trujillo - Liceo), e cinco estações localizadas nas regiões circunvizinhas, (Boconó, Santiago de Trujillo, Valera -Aereopuerto, Pampán e Santa Ana) e se obteve a precipitação média anual para cada estação e logo para o intervalo de tempo mencionado, a seguir se construiu uma camada de pontos que foi interpolada seguindo o método Kriging, mais adequado a esses tipos de dados.

O SIG utilizado nesta pesquisa foi o software livre e de fonte aberta ILWIS (Integrated Land and WaterIn formation System - Sistema Integrado de Informações para Terra e Água), na versão 3.4, este é considerado pelos seus criadores o Instituto para as Ciências da Geoinformação e Observação da Terra (Institute for Geo-Information Science and Earth Observation ITC), da Universidade de Twente, como um software que combina ferramentas para o sensoriamento remoto assim como também as próprias dos SIG's.

\section{Normalização das camadas}

Como as camadas apresentam diferentes nomenclaturas, é dizer, representam distintos tipos de informação espacial, se faz necessária a reclassificação para uma escala única que permita uma integração sob o ambiente SIG's. Neste trabalho adotou-se o Método do Valor Máximo, o qual consiste em dividir os valores de cada mapa por seu máximo valor a encontrar (EASTMAN, et al., 1995; MALCZEWSKI, 1996; CASTELLANOS e VAN WESTEN, 2005; ROA, 2007, SEGOVIA e ROA, 2012; MONCADA e OJEDA, 2018). Após a normalização das camadas, os valores representativos ficaram entre 0 e 1,sendo que valores próximos de 1 representam as áreas de maior fragilidade ambiental, enquanto os valores próximos de 0 representam as áreas com menores probabilidades de sofrer danos.

Este método foi aplicado nas camadas de declividade e precipitação, no caso da camada de distância até as drenagens foi necessário fazer uma inversão dos valores arranjados, assim as áreas mais próximas das drenagens passaram a obter valores pertos de 1. Na camada de solo, a normalização foi realizada segundo critérios teóricos relacionados à vulnerabilidade deles à erosão, levando finalmente á escala já mencionada.

\section{Segunda etapa: Ponderação/Integração}

Na seguinte etapa denominada Ponderação/Integração foram ponderadas as camadas com a técnica AHP e integradas no SIG utilizando a Combinação Linear Ponderada (CLP). Para realizar a ponderação das camadas mediante AHP são necessários dois estágios básicos; o primeiro é a estruturação da hierarquia de decisão; construção da matriz de comparação pareada e definição dos valores de importância relativa (peso) de cada fator, e no segundo estágio são feitas as verificações de consistência.

\section{Determinação dos pesos}

Com a finalidade de que cada indicador obtivesse seu peso estatístico de acordo com suas características, estabelece-se uma matriz dos indicadores assinando-lhe um valor de importância, em cada par de critérios se coloca uma ordem de categorias segundo a escala de juízos de valor de Saaty (1981). Esses valores variam de 1 a 9, sendo o valor 1 para critérios de mesma importância, 9 para um

$\begin{array}{llllll}\text { Caminhos de Geografia } & \text { Uberlândia - MG } & \text { v. } 21, \text { n. } 73 & \text { Mar/2020 } & \text { p. 86-97 } & \text { Página } 89\end{array}$


critério de importância absoluta sobre outro e os valores pares $(2,4,6$, e 8) são valores intermediários entre as escalas (GÓMEZ e BARREDO, 2005).

Os graus de importância são utilizados para estabelecer ordem de relevância e intensidade entre os fatores avaliados. Assim o AHP se converte num meio compreensivo, que permite fazer frente aos problemas de decisão representando e quantificando as variáveis envolvidas em uma hierarquia de critérios ponderados por preferências (FARIA e AUGUSTO FILHO, 2013). A tabela 1 apresenta a escala de valores do grau de importância para comparação pareada.

Tabela 1 - Escala de medição para critérios binários do AHP proposto por Saaty.

\begin{tabular}{cl}
\hline Escala & \multicolumn{1}{c}{ Definição e Explicação } \\
\hline $\mathbf{1}$ & Importância igual - os dois fatores contribuem igualmente para o objetivo \\
\hline $\mathbf{3}$ & Importância moderada - um fator é ligeiramente mais importante que o outro \\
\hline $\mathbf{5}$ & Importância essencial - um fator é claramente mais importante que o outro \\
\hline $\mathbf{7}$ & $\begin{array}{l}\text { Importância demonstrada - um fator é fortemente favorecido e sua maior relevância foi } \\
\text { demonstrada na prática }\end{array}$ \\
\hline $\mathbf{9}$ & Importância extrema - a evidência que diferencia os fatores é da maior ordem possível \\
\hline $\mathbf{2 , 4 , 6 , 8}$ & Valores intermediários - possibilidade de compromissos adicionais entre julgamentos \\
\hline
\end{tabular}

\section{Consistência da matriz}

As verificações de consistência de acordo a Gómez e Barredo (2005), são realizadas para que o estudo tenha coerência e pertinência estatística,indicando o nível de coerência do julgamento do avaliador, corrobora-se mediante o uso da Medida Global de Consistência da Matriz (RC) (SAATY, 2005), Equação 1, a seguir:

$R C=I C / I A$

(Equação 1)

Onde: RC: Razão de Consistência; IC: índice de consistência; IA: índice aleatório.

O IC é obtido pelo Eigen principal ( $\lambda$ Max), ou seja, o valor maior das somatórias por linha, usando a Equação 2 proposta também por Saaty (2005), e amostrada a seguir:

$$
\mathrm{IC}=\lambda \operatorname{Max}-\mathrm{N} / \mathrm{N}-1
$$

Sendo: $\lambda$ Max: Eigen Principal; N: numero de variáveis.

O IA, representa o índice de consistência da matriz recíproca gerada aleatoriamente, desde uma escala de 1 até 9 , com juízos de valor recíprocos e diagonal= 1 , de tal modo, Saaty determinou uma tabela de variáveis segundo o tamanho da matriz. Tabela 2, amostrada a seguir.

Tabela 2 - Índices aleatórios para matrizes proposto por Saaty, para o AHP.

\begin{tabular}{cccccccccccc}
\hline $\begin{array}{c}\text { Tamanho da } \\
\text { matriz }\end{array}$ & $1 \times 1$ & $2 \times 2$ & $3 \times 3$ & $4 \times 4$ & $5 \times 5$ & $6 \times 6$ & $7 \times 7$ & $8 \times 8$ & $9 \times 9$ & $10 \times 10$ & $11 \times 11$ \\
\hline Valor aleatório & 0 & 0 & 0,58 & 0,90 & 1,12 & 1,24 & 1,32 & 1,41 & 1,45 & 1,49 & 1,54 \\
\hline & \multicolumn{8}{c}{ Fonte: Saaty $(2005)}$.
\end{tabular}

O valor do RC deve ser igual ou menor que 0,10 para que tenha validade estatística. Valores inferiores a 0,10 podem ser estatisticamente válidos. Caso o RC não se aproxime destes valores, é necessário revisar os juízos de valor assinados no método de comparação da matriz inicial.

Uma vez estabelecidas as ponderações respectivas para cada camada mediante as tabelas de AHP, foi necessária a aplicação da Combinação Linear Ponderada que constitui a técnica de integração das camadas critério, isto é um processo de combinação aditivo compensatório, no qual é necessário ponderações nas camadas em relação ao grau de importância que estas possuem, por sua vez, o peso de cada unidade espacial é conseqüência da adição dos produtos de cada camada critério por sua ponderação relativa, levando o anterior a consolidação da camada proposta, sendo neste caso um

$\begin{array}{llllll}\text { Caminhos de Geografia } \quad \text { Uberlândia - MG } & \text { v. 21, n. } 73 & \text { Mar/2020 } & \text { p. 86-97 } & \text { Página } 90\end{array}$


modelodos distintos níveis de fragilidade ambiental potencial na bacia hidrográfica do rio Castán na Venezuela.

\section{RESULTADOS E ANÁLISE}

Conforme exposto anteriormente, realizou-se um inventário que incluiu uma análise segmentada das variáveis: declividade, distância até drenagens, solos, e distribuição média das precipitações e logo, em virtude das diferentes terminologias apresentadas pelas camadas foi necessária fazer uma normalização das mesmas, usando o Método do Valor Máximo.

O conhecimento da declividade do terreno permite a prevenção da perda de solo, além de ser ferramenta para o manejo e a gestão dos recursos hídricos, especificamente no mapeamento de águas subterrâneas, e no planejamento adequado do uso da terra; por exemplo $15 \%$ de declividade é o limite máximo para uso de maquinaria agrícola. A figura 2 apresenta a distribuição espacial das classes de declividade da bacia do rio Castán, indicando que somente nas proximidades das drenagens e nas divisórias apresentam-se zonas planas.

A rede de drenagem estão embasadas por 3 sub-bacias: a do rio Mocoy, possui extensão territorial 179,85 km² e suas principais drenagens são: o Mocoy, a Quebrada La Honda e a Quebrada Seca, a sub-bacia do rio Castán que tem uma extensão territorial $163,99 \mathrm{~km}^{2}$, pode ser considerada a de maior importância, conta com a presença dos cursos de água: Quebrada Los Cedros e Quebrada de Ramos e terceira e menor das sub-bacias é a da Quebrada de Agua Clara com uma extensão territorial de $53,10 \mathrm{~km}^{2}$. O comprimento do curso d'água principal é de $40,765 \mathrm{~km}$, e a bacia do rio Castan apresenta $3^{\mathrm{a}}$ ordem. Em relação à densidade de drenagem, na área estudada é de $0,37 \mathrm{~km}$ de curso d'água/ $/ \mathrm{km}^{2}$ o que é representativo de áreas com boa drenagem, portanto deveria ter uma resposta rápida ao influjo da precipitação (Figura $2 b$ ).

A classificação de solos apresentada tem suas origens na proposta feita pelo Serviço de Conservação dos Solos (EUA) e estabelece suas capacidades com fins agropecuários. O tipo de solo com maior representatividade na bacia hidrográfica do rio Castán é o solo de tipo VII (em suas três subcategorias: VII_Te(1)-O , VII_Te(2)-P , e VII_Te_(4)-R) computando 59\% da superfície da bacia, esses são solos residuais, o que é sinônimo de que permanecem no local de decomposição da rocha que lhes deu origem. Nesses solos o risco á erosão é alto, a fertilidade natural é baixa e tem pouca profundidade efetiva, dependendo de características associadas com a declividade pode ser recomendado o cultivo de certos itens agrícolas como café, hortaliças ou só seu uso recreativo.

O outro tipo de solo que segue por sua proporção é o tipo VIII (categorias: VIII_Te(1)-S e VIII_Te(3)$U$ ), que representam $29 \%$ do território; estes também são solos residuais, com grandes riscos de erosão encontrados em relevo ondulado ou montanhoso, o que limita seu uso agrícola a práticas conservacionistas ou com grandes cuidados ambientais. Em menores proporções se tem solos de tipo $\mathrm{V}$ e $\mathrm{VI}$, que são característicos de relevos com menores declividades localizando-se no vale do rio Castán e em algumas zonas nos interflúvios de água. Outro tipo de solo encontrado na bacia é o distintivo de Páramo, recomendado para a recreação e a vida silvestre em virtude das temperaturas baixas do entorno, sendo muito difícil o desenvolvimento de culturas agrícolas (Figura 2c).

A última característica descrita foi a distribuição média das precipitações, sendo que o arquétipo de chuvas correspondem ao padrão bimodal, próprio da bacia do Lago de Maracaíbo, com duas máximas de precipitação anuais uma em maio e outra em outubro (CORPORACIÓN DE LOS ANDES, 2006), a média anual é de aproximadamente $1.500 \mathrm{~mm}$ anuais, a máxima precipitação se localiza na região sul da bacia em quanto o mínimo corresponde às regiões localizadas ao norte da mesma, influenciando de maneira direita o comportamento da vegetação, embora seja uma variação pouco significativa(Figura 2d). A figura 2 a apresenta as camadas geradas e na figura 3 são apresentadas as camadas normalizadas. 
Figura 2 - Camadas geradas no SIG: a) Declividade; b) Distância até as drenagens; c) Solos e d) Precipitação

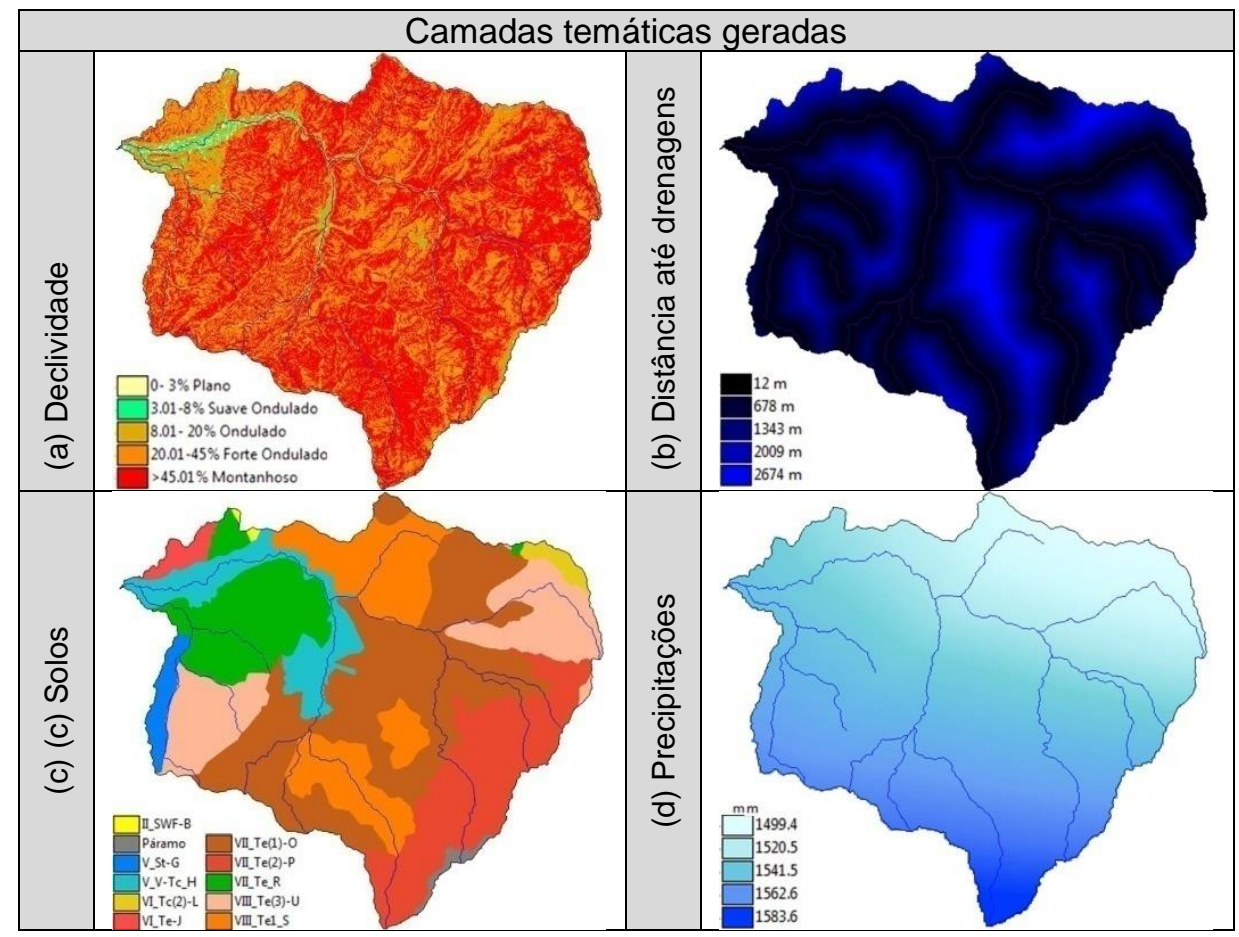

Fonte: Os autores.

Figura 3 - Camadas Normalizadas no SIG: a) Declividade; b) Distância até as drenagens; c) Solos e d) Precipitação.

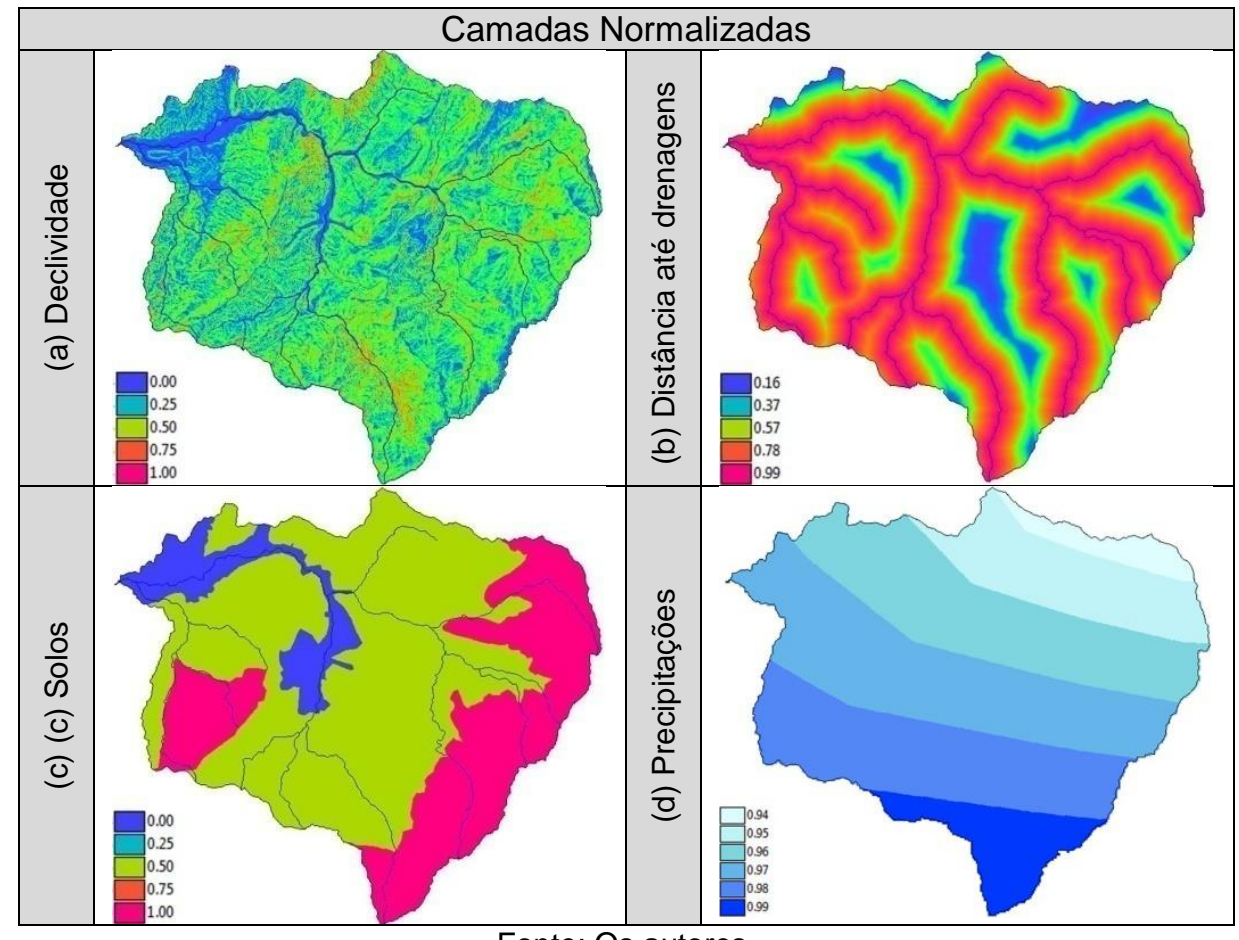

Fonte: Os autores.

Após a geração e normalização das camadas realizou-se Ponderação/Integração, que corresponde à concretização da matriz de comparação pareada; os níveis de importância para a matriz de comparação par a par foram definidos tendo em consideração o julgamento técnico de especialistas de acordo com a finalidade do método, resultando nos valores indicados na tabela 3.

\begin{tabular}{llllll}
\hline Caminhos de Geografia & Uberlândia - MG & v. 21, n. 73 & Mar/2020 & p. 86-97 & Página 92
\end{tabular}


Tabela 3 - Matriz de Comparação Pareada suporte do AHP para o diagnóstico de fragilidade ambiental potencial da bacia hidrográfica do rio Castán em Trujillo-Venezuela.

\begin{tabular}{ccccc}
\hline Critérios & Precipitação & $\begin{array}{c}\text { Distância até as } \\
\text { drenagens }\end{array}$ & Solos & Declividade \\
\hline Precipitação & 1.00 & 2.00 & 3.00 & 1.00 \\
\hline $\begin{array}{c}\text { Distância até as } \\
\text { drenagens }\end{array}$ & 0.50 & 1.00 & 3.00 & 0.33 \\
\hline Solos & 0.33 & 0.33 & 1.00 & 0.33 \\
\hline Declividade & 1.00 & 3.00 & 3.00 & 1.00 \\
\hline \multicolumn{5}{c}{ Fonte: Os autores. }
\end{tabular}

Conseguiu-se como fator de maior importância na avaliação da fragilidade ambiental potencial, a declividade do terreno, representando $37,5 \%$ de importância na para a avaliação multicritério, seguida da Precipitação com um 33,6\%, logo se posiciono acamada de distância até as drenagens com 19\%, e com o menor peso estão os solos representando apenas o 9,9\%. Na tabela 4, apresentada a continuação de detalham os valores mencionados.

Tabela 4 - Pesos finais por ordem decrescente de importância.

\begin{tabular}{lrc}
\hline \multicolumn{1}{c}{ Fatores } & Pesos finais & Pesos (\%) \\
\hline Declividade & 0,375 & 37,5 \\
\hline Precipitação & 0,336 & 33,6 \\
\hline Distância até as drenagens & 0,190 & 19 \\
\hline Solos & 0,099 & 9,9 \\
\hline \multicolumn{1}{c}{ Total } & 1,000 & 100 \\
\hline
\end{tabular}

Fonte: Os autores.

Para o cálculo do índice e a razão de consistência da AHP, foi necessário após cumprimento dos procedimentos de estruturação da matriz de comparação pareada, sua normalização e cálculo de autovetores. A continuação na tabela 5 é apresentada a matriz comparativa normalizada do grupo de critério, com sua respectiva coluna de vetor de Eigen e de Eigen Principal ( $\lambda$ Max), para obter esse valor é necessário a aquisição da média das consistências, que é o somatório do produto de cada valor atribuído na comparação par a par, da Matriz principal de fatores de importância, dividido pelo vetor de Eigen encontrado para cada fator. Vale lembrar que o Eigen Principal ( $(M a x)$, é utilizado para a verificação do Índice e Razão de Consistência.

Tabela 5 - Matriz comparativa normalizada do grupo de critérios com o cálculo de autovetores e eigen principal ( $\lambda$ Max).

\begin{tabular}{lcccccc}
\hline Criritérios & Precipitação & $\begin{array}{c}\text { Distância até } \\
\text { as drenagens }\end{array}$ & Solos & Declividade & $\begin{array}{c}\text { Vetor de } \\
\text { Eigen }\end{array}$ & $\begin{array}{c}\text { Eigen Principal } \\
(\text { MMax })\end{array}$ \\
\hline Precipitação & 0.35 & 0.32 & 0.30 & 0.38 & 1.387 & 4.130 \\
\hline $\begin{array}{l}\text { Distância até } \\
\text { as drenagens }\end{array}$ & 0.18 & 0.16 & 0.30 & 0.13 & 0.779 & 4.106 \\
\hline Solos & 0.12 & 0.05 & 0.10 & 0.13 & 0.399 & 4.040 \\
\hline Declividade & 0.35 & 0.47 & 0.30 & 0.38 & 1.577 & 4.202 \\
\hline & & & & Eigen Principal $\lambda$ Max & 4.119 \\
\hline
\end{tabular}

Fontes: Os autores.

Após a construção da matriz determinou-se o índice de consistência como passo prévio para a construção da Medida de Consistência Global da Matriz, aplicando a equação 2, obtendo o valor de IC igual a 0,04 . 
Com a intenção de verificar e validar que os pares e os pesos assinados aplicou-se a RC, mencionada na equação 1. O procedimento consiste na divisão entre o IC $(0,04)$ e o IA (IA igual 0,9 de acordo com a tabela 2), resultando num valor de RC igual a 0,044.

Se o valor de RC é menor que 0,10 considera-se dentro dos limites aceitáveis, indicando uma consistência apropriada dos juízos, assim, as comparações realizadas neste trabalho foram coerentes e geraram resultados confiáveis, ratificando que a matriz foi preenchida de maneira aleatória e consistente.

Uma vez padronizados e processados os mapas gerados como coberturas de critérios se combinam tomando em consideração os pesos relativos calculados na matriz AHP. A CLP constituiu a técnica de integração das camadas critério, no qual são necessárias ponderações nas camadas, em relação ao grau de importância que estas possuem, por sua vez, o peso de cada unidade espacial é consequência da adição dos produtos de cada camada critério por sua ponderação relativa. A equação 3 representa a CLP correspondente para a modelagem da fragilidade ambiental potencial da bacia hidrográfica do rio Castán.

$$
\begin{gathered}
\text { Diagnóstico de fragilidade ambiental potencial= } \\
\begin{array}{c}
0,38 \text { (Declividade) }+0,34 \text { (Precipitação) }+0,19 \text { (Distância até as } \\
\text { drenagens) }+0,10 \text { (Solos). }
\end{array}
\end{gathered}
$$

(Equação 3)

Após da aplicação da equação 3, obteve-se como produto o mapa temático denominado Fragilidade ambiental potencial da bacia hidrográfica do rio Castán que é amostrado na figura 4 . O mapa apresenta inicialmente valores entre 0 e 1 , (valores próximos de 0 simbolizam baixos níveis de fragilidade ambiental potencial, e valores pertos de 1, são os que possuem maiores níveis de fragilidade ambiental potencial), em virtude que o usuário final requere uma categorização simples para o entendimento do modelo o mesmo foi classificado em 5 níveis de fragilidade ambiental a saber, Muito Baixa, Baixa, Moderada, Alta e Muito Alta, usando as inflexões do histograma de frequência.

Figura 4. Fragilidade ambiental potencial da bacia hidrográfica do rio Castán.

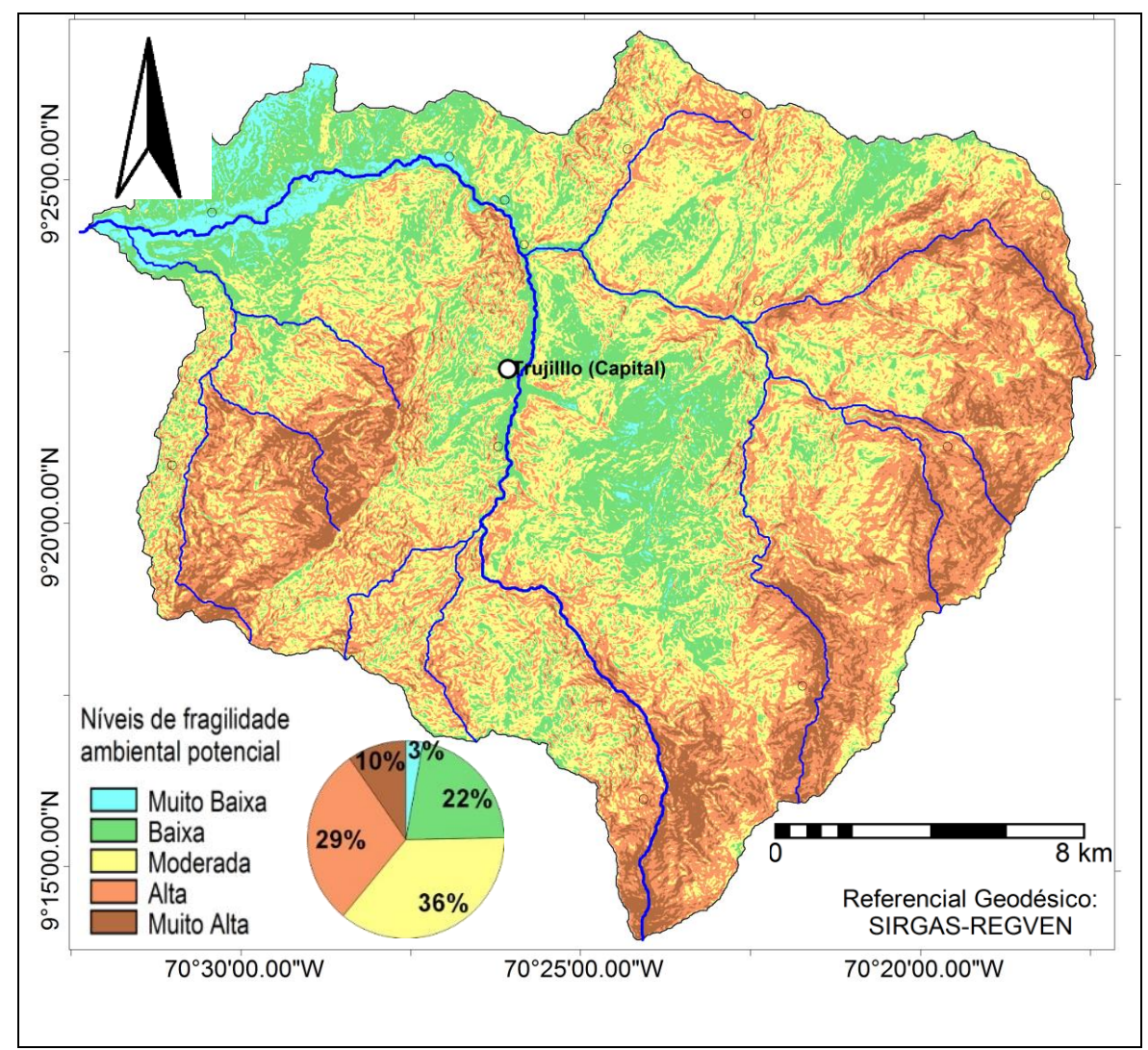

Fontes: Os autores. 
A figura 4 mostra que as áreas com menor nível de fragilidade ambiental potencial, classificada no mapeamento como Muito Baixa localizam-se na zona noroeste da bacia, na planície formada pelo rio Castán, especificamente no vale, a extensão aproximada das mesmas é de $11,9 \mathrm{~km}^{2}$. As áreas de Baixo nível de fragilidade ambiental potencial resumem $87,3 \mathrm{~km}^{2}$ de extensão territorial, é importante mencionar que a cidade de Trujillo encontra-se localizada em uma zona que possui esta característica. A fragilidade ambiental potencial Moderada simboliza um $36 \%$ da área total da bacia hidrográfica do rio Castán com uma área aproximada de $142,9 \mathrm{~km}^{2}$.

Observa-se a predominância das classes onde a fragilidade ambiental potencial é Alta e Muito Alta, as quais somadas representam $154,8 \mathrm{~km}^{2}$, estas áreas se localizam majoritariamente nas zonas das nascentes, onde confluem as maiores declividades, os solos são erodíveis e há maior incidência das precipitações. Em virtude dos resultados acima, recomenda-se que estas características sejam consideradas na elaboração de planos de desenvolvimento agrícola.

Também é necessário o incremento de medidas de manejo para a conservação e restauração de ecossistemas, em virtude do aumento das áreas agrícolas localizadas em áreas de Alta e Muito Alta fragilidade ambiental potencial, sem considerar um devido planejamento, ocasionado uma aceleração dos processos erosivos e de ruptura do equilíbrio sistêmico.

\section{CONSIDERAÇÕES FINAIS}

As técnicas de análise multicritério utilizadas em ambiente SIG's, demonstraram eficácia na realização da modelagem cartográfica da fragilidade ambiental potencial na bacia hidrográfica do rio Castán no estado Trujillo - Venezuela. A AHP tem entre suas características a diminuição da subjetividade, com um $\mathrm{RC}$ dentro das medidas estatísticas de validação

Por ser uma metodologia maleável, possibilita a adaptação de novos fatores; de acordo com a disponibilidade de imagens orbitais de alta resolução que favorecem o posterior trabalho cartográfico e das condições da área de estudo, assim o número de critérios (camadas), poderia aumentar fazendo a modelagem final mais robusta e representativa da realidade presente no espaço geográfico estudado.

O trabalho tenta ademais promover e colaborar com a discussão de metodologias a serem empregadas na elaboração de estudos ambientais, levando em consideração os avanços na aquisição e processamento da informação geográfica. A aplicação de métodos, como o usado nesta pesquisa, possibilitou estimar as vantagens e desvantagens da cartografia automatizada na geração deste tipo de produtos cartográficos, sendo isso de especial interesse no desenvolvimento de trabalhos similares no futuro.

A utilização deste estudo pode contribuir para a realização de outros mapeamentos e diagnósticos, seja mediante a complementação e adaptação do mesmo, ou como ponto de partida para a criação de programas voltados à recuperação e adequação de áreas segundo os resultados apresentados nesta pesquisa.

\section{AGRADECIMENTOS}

Expressamos nosso agradecimento ao Programa de Alianças para a Educação e a Capacitação patrocinada pela Organização dos Estados Americanos (OEA) e o Grupo Coimbra de Universidades Brasileiras (GCUB), por intermediário de CAPES pela bolsa concedida para a realização do Mestrado em Geografia e, portanto, da pesquisa que embasou a redação desse artigo.

\section{REFERÊNCIAS}

CASTELLANOS, A. E. A.; VAN WESTEN, C. J. Development of a system for landslide risk assessment for Cuba. In HUNGR, O.; FELL, R.; COUTURE, R.; EBERHARDT, E. (Coord.) Proceedings of the international conference on landslide risk management. Vancouver: Balkema, 2005. P. 1-10.

CORPORACIÓN DE LOS ANDES. Dossier Municipal 2006 - Pampanito. 2006. Disponível em:http://www.corpoandes.gov.ve/files/imagenes/file/descargas/gerencia_informacion/dossiers/dosierr

\begin{tabular}{llllll}
\hline Caminhos de Geografia & Uberlândia - MG & v. 21, n. 73 & Mar/2020 & p. 86-97 & Página 95
\end{tabular}


\%20corregido\%20definitivo\%202006/Dossier\%20Trujillo\%20PDF/dossier\%20municipal\%202006/Dos sier\%20Pampanito\%202006.pdf . Acesso em: 21 março 2017.

EASTMAN, J. R. Decision Support: Decision Strategy Analysis. In: Clark University (Ed.). IDRISI Andes Guide to GIS and Image Processing. Worcester: Clark Labs, 2006.

EASTMAN, J. R.; JIN, W; KYEM, P. A.K.; TOLEDANO J. Raster procedures for multi-criteria/multiobjective decisions. Photogrammetry and Remote Sensing, v.61, p. 539- 547, 1995.

FARIA, D. G. M.; AUGUSTO FILHO, O. Aplicação do Processo de Análise Hierárquica (AHP) no mapeamento de perigo de escorregamentos em áreas urbanas. Revista do Instituto Geológico, São Paulo, v. 34, n. 1, p. 23-44, 2013. https://doi.org/10.5935/0100-929X.20130002

FERREIRA, C.C. Proposta de zoneamento ambiental das paisagens para o alto curso da bacia hidrográfica do rio Sucuriú, Mato Grosso do Sul-Brasil. Tese (Doutorado em Geografia) - Presidente Prudente: Universidade Estadual Paulista "Julio De Mesquita Filho". 2016.

FRANÇA, L. C. J. Fragilidade ambiental potencial da bacia hidrográfica do rio Jequitinhonha, Minas Gerais, Brasil. Dissertação (Mestrado) - Minas Genais: UFVJM. 2018.

GÓMEZ, M.; BARREDO, J. Sistemas de información geográfica y evaluación multicriterio en la ordenación del territorio. Madrid: Editorial Ra-Ma. 2005.

HORN, B. K. P. Hill shading and the reflectance map. Proceedings of the IEEE, n. 69, v. 01, p. 14-47, 1981. https://doi.org/10.1109/PROC.1981.11918

JAXA. (2015). Advanced Land Observing Satellite data / ALOS - Advanced Land Observing Satellite data. Descargado de http://www.alos-restec.jp/en/

KAWAKUBO, F. S.; MORATO, R. G.; CAMPOS, K. C.; LUCHIARI, A.; ROSS, J. L. S. Caracterização empírica da fragilidade ambiental utilizando geoprocessamento. In: Anais XII Simpósio Brasileiro de Sensoriamento Remoto, Goiânia, Brasil, 16-21 abril 2005, INPE, p. 2203-2210. Disponível em:< http://marte.sid.inpe.br/col/tid.inpe.br/sbsr/2004/11.19.16.10/doc/2203.pdf>

MALCZEWSKI, J. A GIS-based approach to multiple criteria group decision making. International Journal $\begin{array}{lllll}\text { of Geographical Information Systems, v.10, } & \text { p.955-971, } & 1996 .\end{array}$ https://doi.org/10.1080/02693799608902119

MONCADA J.V.L.; Ojeda E.C. Aproximación al mapa de susceptibilidad a inundación en la cuenca del río Boconó, Estado Trujillo, Venezuela. Terra Nueva Etapa, v.34, p. 119-140, 2018.

PAGOT, M. Metodologías inductivas y deductivas en técnicas de Teledetección. Córdoba: Editorial Universitas. 2003.

ROA, J. Estimación de áreas susceptibles a deslizamientos mediante datos e imágenes satelitales: cuenca del río Mocotíes, estado Mérida-Venezuela. Revista Geográfica Venezolana, v.48, p.183-219, 2007.

SAATY, T. L. Método de análise hierárquica. São Paulo: Makron Books. 1981.

SAATY, T. L. Theory and Applications of the Analytic Network Process: Decision Making with Benefits, Opportunities, Costs, and Risks. Pittsburgh: RWS Publications, 2005.

SCHIAVO, B. N. V.; HENTZ, A. M. K.; DALLA CORTE, A. P.; SANQUETTA, C. R. Caracterização da fragilidade ambiental de uma bacia hidrográfica urbana no município de Santa Maria - RS. Rev. Eletrônica em Gestão, Educação e Tecnologia Ambiental, v.20, n.1, p.464-473, 2016.

SEGOVIA, L.; ROA. J. Evaluación de la potencialidad del cultivo de chachafruto en la microcuenca del río Monaicito, Trujillo-Venezuela, a través de SIG y EMC. AGORA, v.15 n. 29, p. 109-133, 2012. 
SPORL, C. Metodologia para elaboração de modelos de fragilidade ambiental usando redes neurais. Tese (Doutorado em Geografia) - São Paulo: USP. 2007.

VALLE, I. C.; FRANCELINO, M. R.; PINHEIRO, H. S. K. Mapeamento da Fragilidade Ambiental na Bacia do Rio Aldeia Velha, RJ. Floresta Ambiente, v. 23, n. 2, p. 295-308, 2016. https://doi.org/10.1590/2179-8087.107714

VALERA, F.; CASTELLANO, A. Dinámica del uso de la tierra en la cuenca del río Castán, Trujillo Venezuela, 1996-2001. Trujillo - Venezuela: ACADEMIA. v. 9, n. 18, p. 61-72, 2010.

Recebido em: 07/03/2019

Aceito para publicação em: 12/08/2019 